\title{
Prediction of maximal aerobic power from a submaximal exercise test performed by paraplegics on a wheelchair ergometer
}

\author{
G Paré MSc MD ${ }^{1}$ L Noreau $\mathrm{PhD},{ }^{* 1,2} \mathrm{C}$ Simard $\mathrm{PhD}^{1,3}$
}

${ }^{1}$ Adapted Physical Activity Evaluation Laboratory, Centre François-Charon, 525 Boulevard Hamel, Quebec City, Quebec, Qc, Canada G1M 258; ${ }^{2}$ Department of Physical Therapy, ${ }^{3}$ Department of Physical Education, Laval University, Quebec City, Quebec, Qc, Canada.

The aim of the present study was to verify the basic principles underlying the prediction of $\dot{\mathrm{VO}}_{2}$ peak from a submaximal exercise test performed by paraplegics on a wheelchair ergometer and thus to propose regression equations of $\mathrm{VO}_{2}$ peak prediction. Forty-six paraplegic subjects (mean age $=33.2 \pm 8.7$ years) with a traumatic lesion (T1-L3) performed a graded exercise test on a wheelchair ergometer until exhaustion. The test started with an initial workload of 0 watts, with an increment of 6 watts per 2 minutes. Measurements included power output $(\mathrm{W})$, heart rate $(\mathrm{HR})$ and oxygen consumption $\left(\dot{\mathrm{VO}}_{2}\right)$ throughout the test. Linear relationships were observed between $\dot{\mathrm{VO}} \mathrm{O}_{2}$ and $\mathrm{W}\left(\mathrm{VO}_{2}=\right.$ $0.79+0.02 \mathrm{~W}, r=0.80, \mathrm{SEE}=0.221 \mathrm{~min}^{-1}$ ) as well as between $\% \dot{\mathrm{VO}} \mathrm{O}_{2} \max$ and $\%$ maximal heart rate $\left(\% \dot{\mathrm{VO}}{ }_{2} \max =8.7+0.83 \% \mathrm{HR}, r=0.83 \mathrm{SEE}=\right.$ $10.5 \%)$. Combination of the two equations for estimating $\dot{\mathrm{VO}}_{2}$ peak led to a linear relationship between the estimated and measured $\dot{\mathrm{V}} \mathrm{O}_{2}$ peak. Nonetheless, the strength and accuracy of the prediction were low $(r=0.49, \mathrm{SEE}=$ $\left.0.291 \mathrm{~min}^{-1}\right)$. Participation in aerobic exercise, body mass and lean body mass, introduced as correction factors in the regression equation, significantly improved the strength and the accuracy of the prediction $(r=0.85, \mathrm{SEE}=$ $\left.0.291 \mathrm{~min}^{-1}\right)$. These results showed that the relationship between physiological variables $\left(\dot{\mathrm{V}}_{2}\right.$ peak $-\mathrm{W}, \% \dot{\mathrm{VO}}_{2}$ peak $\left.-\% \max \mathrm{HR}\right)$ during wheelchair exercise in paraplegics are linear but, in some instances, much variability is observed, suggesting a need for further research in order to improve the accuracy of $\dot{\mathrm{VO}}_{2}$ peak prediction.

Keywords: paraplegia; exercise testing; aerobic power; wheelchair exercise.

\section{Introduction}

Procedures of predicting maximal aerobic power $\left(\dot{\mathrm{VO}}_{2} \max \right)$ from a submaximal exercise test were developed following the works of Astrand and Ryhming. ${ }^{1}$ Since then, many studies have contributed to improve the accuracy of these procedures on bicycle ergometer $^{2,3}$ as well as on treadmill. ${ }^{4,5}$ Very few studies reported procedures for the prediction of peak oxygen consumption $\left(\dot{\mathrm{V}}_{2}\right.$ peak) from a submaximal exercise

\footnotetext{
${ }^{*}$ Correspondence.
}

performed with the upper limbs, ${ }^{6,7}$ even though a first report on upper body exercise was presented in 1924 by Collett and Liljestrand. ${ }^{8}$ The number of reports decrease if we consider the investigations in disabled persons such as the individuals with spinal cord injury (SCI). ${ }^{9-11}$

The development of procedures to predict $\dot{\mathrm{V}} \mathrm{O}_{2}$ peak was motivated by the fact that newly spinal cord injured persons are unable to perform a maximal exercise test during the initial stage of rehabilitation considering their low level of fitness following hospitalization, the potential adverse reaction to 
maximal exercise and the risk of vertebral fractures. Thus, a submaximal test would be more appropriate to assess $\dot{\mathrm{VO}}_{2}$ peak of such individuals and may be helpful for the prescription of a safe and meaningful exercise program early in rehabilitation.

The most popular ergometer described in studies on $\dot{\mathrm{VO}}_{2}$ peak prediction during upper body exercise is the arm cranking ergometer (ACE) ${ }^{12}$ Kofsky et al ${ }^{11}$ reported equations to predict the $\dot{\mathrm{VO}}_{2}$ peak with 49 paraplegic subjects using a three stage submaximal and a maximal exercise test performed on ACE. For 35 male subjects, the predictive power of the submaximal test was fair $(r=0.67)$. A prediction equation of oxygen uptake from power output was reported by Hjeltnes ${ }^{10}$ from a three stage submaximal exercise test performed on ACE. A high correlation $(r=0.97)$ was observed but the study had a limited number of subjects $(n=9)$ and the standard error of estimate was not reported.

The concept of exercise specificity ${ }^{13}$ suggests that meaningful evaluation of wheelchair-bound individuals requires wheelchair-type activity as the exercise mode. ${ }^{14}$ In the past, different wheelchair devices were used to assess the exercise capacity of persons with SCI: (1) wheelchairs overground ${ }^{15,16}$ or mounted on a treadmill $^{17,18}$ or on low-friction rollers; ${ }^{19,20}$ (2) wheelchair ergometers with a Monarktype friction $^{9,21}$ or an electromagnetic braking system. ${ }^{22}$

The aim of the present study was to verify the basic principles underlying the prediction of $\dot{\mathrm{V}} \mathrm{O}_{2}$ peak from a submaximal exercise test performed by paraplegic subjects on a wheelchair ergometer in order to develop a clinical procedure of $\dot{\mathrm{VO}} \mathrm{O}_{2}$ peak prediction that could be used in rehabilitation.

\section{Methods}

\section{Subjects}

Basic criteria for potential inclusion in the study were: (1) age 16-59 years; (2) male subjects; (3) traumatic lesion; (4) lesion level $\mathrm{T} 1$ or lower (corresponding to the International Stoke Mandeville Games Federation classes II-V); $;^{23}$ (5) at least 3 years postinjury; (6) ability to perform a maximal exercise test on a wheelchair ergometer.

Most of the subjects were recruited through mail contact from the 'Société d'assurance automobile du Québec' files. Forty-six subjects (mean age 33.2 \pm 8.6 years) agreed to participate in the study. More than $67 \%$ of them had sustained their injury between 13 and 32 years of age and mean posttraumatic period was $10.7 \pm 6.5$ years.

\section{Instrumentation}

The wheelchair ergometer used for the present study was designed by members of our laboratory with the cooperation of the Mechanical Engineering Department of Laval University in Quebec City (Fig 1). Basically, a standard wheelchair was mounted on a metal frame; then, the two wheels were coupled to an electromagnetic braking system placed behind the seat. Universal joints allowed the tilting of the wheels simulating the inclination of the individual's wheelchair. The seat could be electrically adjusted forward, backward, up and down in order to simulate the subject's best seating. The electromagnetic braking system kept a constant power output (accuracy \pm 0.5 watts) whereas the individual pushed the rim over the range of 40 to 80 rev min $^{-1}$. Thus, the subjects could concentrate on the propelling technique rather than the necessity to keep a constant velocity. Because of the inertia produced by a metal wheel within the braking mechanism,

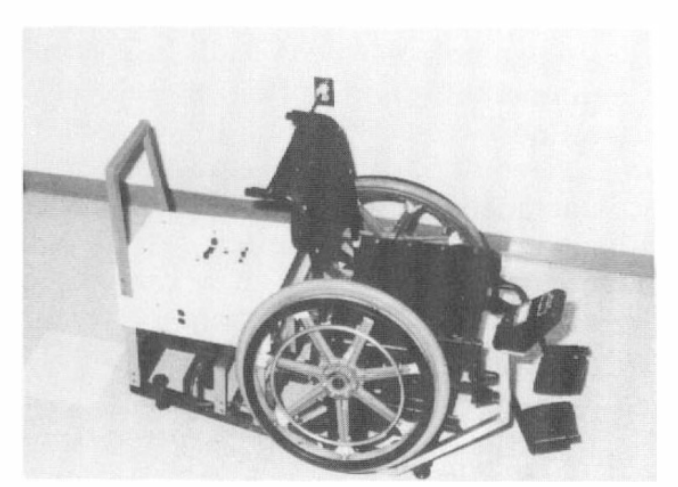

Figure 1 Wheelchair ergometer. 
subjects reported that the wheelchair ergometer nicely simulated the overground locomotion.

\section{Data collection}

The modified physical activity readiness questionnaire which was that currently used in our laboratory was included to allow the team physician to determine in advance subjects who would be at risk for maximal exercise. Subjects' blood pressure and resting EKG were recorded as part of a pretest clinical examination conducted by the team physician. The first physiological variables to be recorded were the measurements made at rest, starting with standard anthropometry: height (supine position) and body mass, allowing the computation of the body mass index $\left(\mathrm{kg} \mathrm{m}^{-2}\right)$. Five skinfold measurements (biceps, triceps, subscapular, suprailiac, calf) were recorded as proposed by Fitness $\mathrm{Canada}^{24}$ using Harpenden calipers. An estimate of the percent body fat was computed from four skinfolds (biceps, triceps, subscapular, suprailiac) as proposed by Womersley \& Durnin. ${ }^{25}$ Furthermore, lean body mass was calculated from percent body fat.

\section{Wheelchair ergometry}

Subjects performed a progressive exercise test to exhaustion on the wheelchair ergometer. They breathed through a low resistance mouthpiece and a two-way valve connected to a metabolic analyser (Morgan) which determined respiratory minute volume, oxygen consumption and $\mathrm{CO}_{2}$ output. The EKG was monitored throughout exercise, using a unipolar CM5 lead. Indications to terminate exercise prior to subjective exhaustion were as specified by the American College of Sports Medicine. ${ }^{26}$ The protocol included a 2 minute warm-up duration without load ( 0 watt). The test started with an initial load of 0 watts at a cadence of $40 \mathrm{rev} \mathrm{sec}^{-1}$, with an increment of 6 watts every 2 minutes until exhaustion.

\section{Activity measurements}

The method proposed by Godin \& Shephard $^{27}$ was adapted and used as a simple index of leisure-time physical activity. An arbitrary total weekly score (T) was derived by summing up the reported weekly participation at each of the three intensity levels (mild, moderate and strenuous), multiplied by a corresponding anticipated metabolic cost of 2, 4 and 7 METS, respectively. This instrument has had substantial validation in various regions of Canada.

\section{Statistical analysis}

The Systat program (version 5.0) for Macintosh was used for data management and analysis. Significance for all statistical analyses was fixed at the 0.05 level. Student's $t$ tests were used to determine whether or not there was a significant difference between the predicted and measured maximal heart rate. Simple regression was used to compute prediction equations and to determine the association between: (1) oxygen uptake and power output, and (2) percentage of $\mathrm{VO}_{2}$ peak and submaximal heart rate. From the two equations, the predicted $\dot{\mathrm{V}} \mathrm{O}_{2}$ peak was computed. Using multiple regression, the influence of various factors (age, physical activity, body mass, level of injury) on the accuracy of prediction was determined. Furthermore, residual scores were calculated in order to assess the mean percentage of error of the predicted $\dot{\mathrm{VO}}_{2}$ peak.

\section{Results}

\section{Anthropometry}

Results on body composition of the sample are presented in Table I. A large range of body mass suggested the inclusion in the study of subjects with different morphology. Nonetheless, most subjects $(83 \%)$ were under the critical value ${ }^{27}$ of an increased

Table I Physical characteristics of the sample $(n=46)$

\begin{tabular}{lrrrr}
\hline Variable & $\bar{X}$ & \multicolumn{2}{c}{ SD } & \multicolumn{2}{c}{ Minimum Maximum } \\
\hline Height $(\mathrm{cm})$ & 176.0 & 9.2 & 155.0 & 200.0 \\
Body mass $(\mathrm{kg})$ & 70.1 & 13.6 & 41.2 & 111.0 \\
BMI $^{\mathrm{a}}\left(\mathrm{kg} \mathrm{m}^{-2}\right)$ & 22.6 & 4.0 & 15.4 & 37.3 \\
LBM $^{\mathrm{b}}(\mathrm{kg})$ & 54.6 & 8.3 & 36.5 & 78.0 \\
\hline
\end{tabular}

${ }^{a}$ Body mass index. ${ }^{b}$ Lean body mass. 
risk of developing cardiovascular diseases in terms of their body mass index..$^{28}$

\section{Physical activity}

Participation in physical activity is important to the social and physical rehabilitation of persons with SCI. Aerobic exercise was limited to an average of one period per week, 22 subjects (48\% of the sample) reporting no participation in such activities. However, an average participation rate of $4.0 \pm 3.9$ times per week in all types of formal exercise indicates that many subjects were participating in some exercise programmes even though the development of cardiovascular health was not a major component of such programs (for example, bowling, wheelchair softball). The large range of the physical activity index $(\bar{X}=$ $16.9 \pm 14.0)$ confirmed that many subjects were totally inactive (low scores) while others had a very active leisure time (high scores).

\section{Response to exercise}

A careful assessment of maximal values attained by each subject during the exercise test indicated that the end-test heart rate of 11 subjects was at least 15 beats below the predicted maximal heart rate $(220-$ age $)$ with some extreme values at 30 beats below the criteria. Thus, these subjects were not considered for the prediction of $\mathrm{VO}_{2}$ peak. Table II summarizes results at maximal exercise. All fitness variables showed a large intersubject variability. The range of power output was 50 watts, and $17 \mathrm{ml} \mathrm{kg}^{-1} \mathrm{~min}^{-1}$ for maximal aerobic power with a value as low as $17.3 \mathrm{ml} \mathrm{kg}^{-1} \mathrm{~min}^{-1}$ suggesting in some individuals a very low level of fitness. No significant differences of $\dot{\mathrm{VO}} 2$ peak were observed with lesion level (over the range of classes II and IV). The mean heart rate reached at maximal exercise $(\bar{X}=187 \pm 11)$ was similar to the predicted maximal heart rate $\left(220-\right.$ age $=187$ beats $\left.\min ^{-1}\right)$.

\section{Oxygen consumption-power output}

The first step to predict maximal aerobic power consisted in the prediction of $\dot{\mathrm{VO}}_{2}$ from power output. A regression line of oxygen consumption on power output (W) from submaximal wheelchair exercise was represented by the linear equation (A). Figure 2 shows the individual data points of measured $\dot{\mathrm{VO}}_{2}$ on power output for all subjects. Despite large variability between subjects, a fair correlation was observed between the two variables.

$$
\begin{aligned}
& \dot{\mathrm{V}} \mathrm{O}_{2}\left(\mathrm{l} \mathrm{min}^{-1}\right)=0.79+0.02 \mathrm{~W}(\text { watts }) \\
& (r=0.80, \mathrm{SEE}=0.22)
\end{aligned}
$$

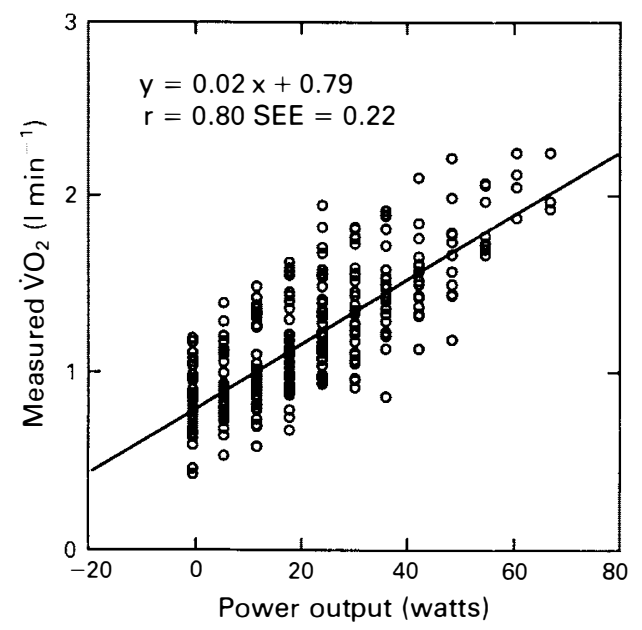

Figure 2 Relationships between measured $\dot{\mathrm{V}} \mathrm{O}_{2}$ and power output through a range of submaximal to maximal exercise.

Table II Results of maximal values from graded exercise testing performed on a wheelchair

\begin{tabular}{|c|c|c|c|c|}
\hline Variable & $\bar{X}$ & SD & Minimum & Maximum \\
\hline Power output (watts) & 38.5 & 13.3 & 18.0 & 66.0 \\
\hline$\dot{\mathrm{V}} \mathrm{O}_{2}$ peak $\left(1 \mathrm{~min}^{-1}\right)$ & 1.63 & 0.36 & 0.96 & 2.54 \\
\hline $\mathrm{VO}_{2}$ peak $\left(\mathrm{ml} \mathrm{kg}^{-1} \mathrm{~min}^{-1}\right)$ & 23.9 & 4.6 & 17.3 & 34.8 \\
\hline Heart rate (beats $\min ^{-1}$ ) & 187 & 11 & 157 & 208 \\
\hline
\end{tabular}
ergometer $(n=35)$ 
\% $\dot{V} \mathrm{O}_{2}$ peak-\% maximal heart rate

The second step consisted in the prediction of the percentage of $\dot{\mathrm{V}} \mathrm{O}_{2}$ peak from a submaximal heart rate (HR) expressed in percentage of reserve heart rate $(\%$ MAX $\mathrm{HR}$, see below). A regression line of $\% \dot{\mathrm{VO}}_{2}$ peak on \% MAX HR was represented by the linear equation (B). The individual data points of all subjects are represented in Figure 3. Despite a fair correlation between the two variables, there exists a lot of variability between the subjects suggesting differences in physiological adaptation to exercise.

$\%$ MAX HR:

$$
\frac{\text { (submax) HR }- \text { (resting) HR }}{\text { (maximal) HR - (resting) HR }}
$$

$\% \dot{\mathrm{VO}}_{2}$ peak $=8.75+0.83 \%$ MAX HR

$(r=0.83, \mathrm{SEE}=10.5)$

\section{Prediction of $\dot{\mathrm{V}} \mathrm{O}_{2}$ peak}

Equations (A) and (B) were combined for estimating $\dot{\mathrm{V}} \mathrm{O}_{2}$ peak from a submaximal power output and a corresponding \% MAX HR. Since maximal values are not attained with a submaximal test, (maximal)HR was replaced into the equation by the predicted

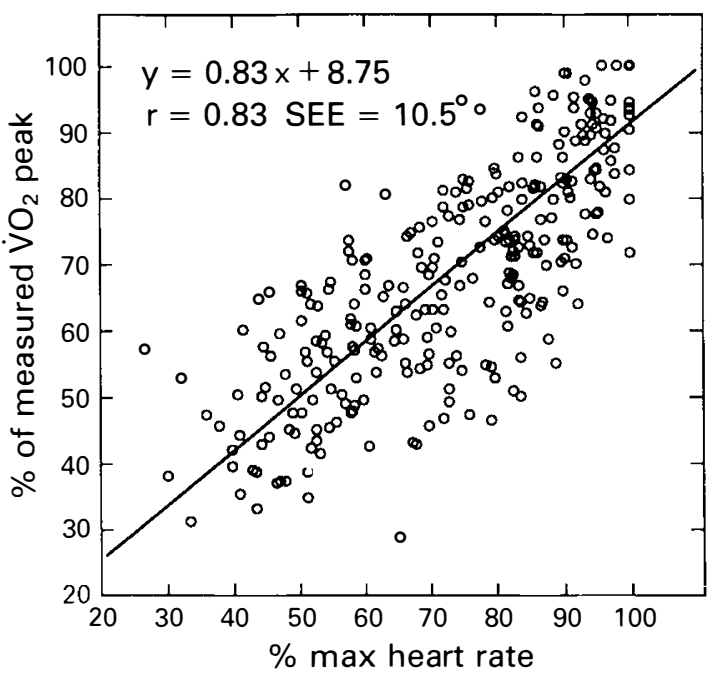

Figure 3 Relationships between \% of measured $\mathrm{VO}_{2}$ peak and \% heart rate through a range of submaximal to maximal exercise. value $(220-\mathrm{AGE})$. Combination of the two equations led to the regression equation (C) of estimated $\dot{\mathrm{VO}}_{2}$ peak.

Estimated $\dot{\mathrm{V}} \mathrm{O}_{2}$ peak $\left(1 \mathrm{~min}^{-1}\right)$

$$
\begin{aligned}
= & {[(0.79+0.02 \mathrm{~W})} \\
& \div(8.75+0.83 \% \mathrm{MAX} \text { HR })] \\
& \times 100
\end{aligned}
$$

Comparison between measured and estimated $\mathrm{VO}_{2}$ peak (Fig 4) showed a fair correlation between the two variables $(r=0.49$, SEE $=0.29)$. Since external factors can influence the prediction of $\dot{\mathrm{VO}}_{2}$ peak, procedures of stepwise multiple regression were used to generate a more accurate prediction with measured $\dot{\mathrm{VO}}_{2}$ peak as a dependent variable and estimated $\dot{\mathrm{VO}}_{2}$ peak, age, level of injury, body mass, lean body mass, level of physical activity as independent variables.

While estimated $\dot{\mathrm{V}}_{2}$ peak contributed for $24 \%$ of the explained variance in measured $\dot{\mathrm{VO}}_{2}$ peak, significant contributions to the prediction were made with the addition of lean body mass $(69 \%$ of variance) or the addition of body mass and participation in aerobic exercise (Table III) leading to an explained variance of $73 \%$ $(r=0.85, \mathrm{SEE}=0.17)$. In a clinical setting,

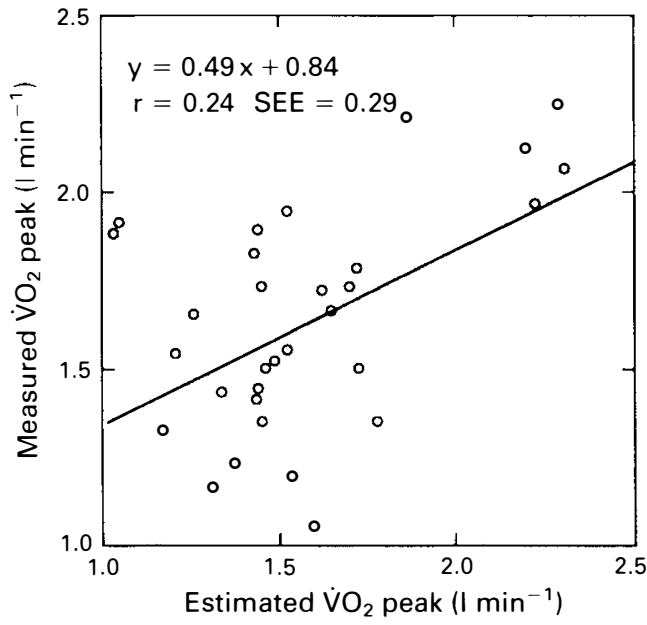

Figure 4 Individual data points for comparison of estimated $\dot{\mathrm{VO}}_{2}$ peak to measured $\dot{\mathrm{VO}}_{2}$ peak. 
Table III The percentage of variance in 'measured $\dot{\mathrm{V}} \mathrm{O}_{2}$ peak' explained by estimated $\dot{\mathrm{V}} \mathrm{O}_{2}$ peak, body mass and aerobic exercise $(n=35)$

\begin{tabular}{llcc}
\hline Step & Independent variables & $r$ & $\%$ variance $\left(r^{2}\right)$ \\
\hline 1 & Estimated $\dot{\mathrm{V}}_{2}$ peak & 0.49 & 0.24 \\
2 & $1+$ body mass & 0.83 & 0.69 \\
3 & $1+2+$ aerobic exercise & 0.85 & 0.73 \\
\hline
\end{tabular}

accurate measurement of lean body mass and aerobic exercise is not always possible. Thus, body mass was introduced with estimated $\mathrm{VO}_{2}$ peak in an equation for predicting measured $\dot{\mathrm{V}} \mathrm{O}_{2}$ peak with a similar percentage of explained variance $(r=0.83$, $\left.\pi^{2}=0.69, \mathrm{SEE}=0.19\right)$ using the following equation (D). Figure 5 shows the individual data points of estimated $\dot{\mathrm{V}} \mathrm{O}_{2}$ peak (corrected value) to measured $\dot{\mathrm{VO}}_{2}$ peak. From residual analysis, the mean error of the estimate of this equation was calculated of $10.7 \%(\mathrm{SD}=8.0 \%)$.

$$
\begin{aligned}
& \text { Corrected } \dot{\mathrm{VO}_{2}} \text { peak }\left(1 \mathrm{~min}^{-1}\right) \\
& =-0.58+0.60 \text { est } \dot{\mathrm{VO}}_{2} \text { peak }\left(1 \mathrm{~min}^{-1}\right) \\
& +0.018 \text { body mass }(\mathrm{kg})
\end{aligned}
$$

\section{Discussion}

While vigorous efforts are made by rehabilitation teams to allow persons with SCI to

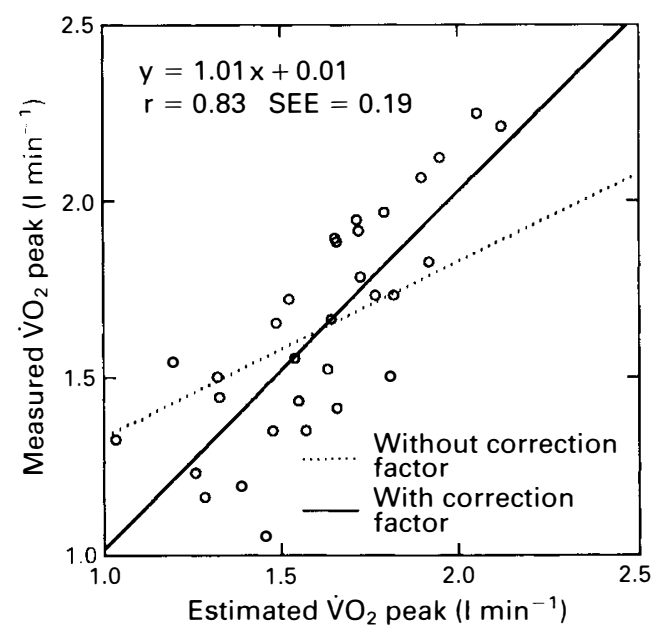

Figure 5 Individual data points for comparison of estimated $\dot{\mathrm{VO}}_{2}$ peak to measured $\dot{\mathrm{VO}}_{2}$ peak with one correction factor (body mass). return to preinjury activities, the physiological aspects of the individual's potential are often unknown. This is particularly true of cardiovascular fitness, since only a few rehabilitation centres own equipment necessary for adapted exercise testing. Nonetheless, there is a need to develop procedures which will allow the assessment of the physical fitness of newly injured paraplegic patients. The aim of the present study was to develop a procedure for the prediction of $\dot{\mathrm{V}} \mathrm{O}_{2}$ peak using a wheelchair ergometer to demonstrate the principle of exercise specificity. Such a procedure would be relevant for the process of exercise prescription in individuals who are medically stable but who are not able to attain maximal exercise.

One of the first principles underlying the prediction of $\dot{\mathrm{VO}} 2$ peak in paraplegic patients that should be considered is the maximal heart rate. Since cardiac function is relatively unaltered following a low-thoracic or lumbar lesion, the predicted maximal heart rate $(220-$ age $)$ may theoretically be reached by most paraplegic patients as by nondisabled during lower body exercise. In fact many studies have suggested that the maximal heart rate during upper body exercise reaches a few beats below the predicted value. In a review of 17 studies on upper body exercise (disabled and nondisabled), Franklin ${ }^{29}$ reported that maximal heart rate reached $88 \%$ to $98 \%$ of maximal value during lower body exercise corresponding to a mean value of 12 beats $\min ^{-1}$ under the prediction.

Mean maximal heart rate observed in the whole sample suggests that the value is not lower than 5 beats $\min ^{-1}$ of the predicted value $(220-$ age $)$. When some individuals $(n=11)$ who seemed not to meet the criteria of maximal exercise are extracted, the observed value is equal to the predicted value. Considering such a result with some 
maximal heart rate over 200 beats $\mathrm{min}^{-1}$, we could hypothesize that physiological adaptation to maximal exercise in a substantial number of individuals with paraplegia (probably well trained) is similar to that observed in nondisabled people. In a previous study by our group,$^{30}$ with a sample of many well-trained wheelchair athletes, we observed that the predicted maximal heart rate has been attained by a majority of subjects. Again, in some individuals, the maximal exercise elicited a heart rate over 200 beats $\min ^{-1}$.

The second principle underlying the prediction of $\dot{\mathrm{V}}{ }_{2}$ peak during wheelchair exercise in paraplegic individuals is the relationship between oxygen consumption and power output. Most of the studies observed a linear relationship between $\mathrm{VO}_{2}$ and power output during wheelchair exercise $e^{9,14,31,32}$ as well as during arm cranking exercise. ${ }^{10,11.33-36}$ In the present study, we observed a linear relationship between $\mathrm{VO}_{2}$ and power output and the correlation coefficient $(r=0.80)$ suggests a fair association even though the value did not reach that presented in previous studies $(r>0.90)$. Differences in subjects, protocols and ergometers might explain this lower value.

The third principle underlying the prediction of $\dot{\mathrm{VO}}_{2}$ peak during wheelchair exercise is the relationship between $\% \dot{\mathrm{VO}}_{2}$ peak and heart rate. Based on the works of Astrand and Rhyming, ${ }^{1}$ this relationship has been seen as linear during lower body exercise. Unfortunately, no studies have published results on this relationship during wheelchair exercise. Our findings showed a linear relationship between the $\% \dot{\mathrm{VO}}_{2}$ peak and the $\%$ of max heart rate $(r=0.83)$ during submaximal exercise but the association between the two variables was not as strong as that presented in studies on bicycle ergometers. ${ }^{3,37,38}$

Interindividual differences in techniques may explain the lower value observed during wheelchair exercise as compared with cycling exercise. Some of our subjects had a very efficient propulsion technique using a complete motion over the wheels while other subjects used a propelling technique over a smaller part of the wheel, diminishing the movement efficiency. Such a discrep- ancy is unlikely to happen in cycling exercise and the range of movement efficiency among individuals is probably smaller.

The combination of the equations (A) and (B) led to an equation predicting $\mathrm{VO}_{2}$ peak with a limited association between measured and estimated values, suggesting the need for introducing correction factors in order to increase the accuracy of prediction. Metz et al $^{39}$ suggested that a regression equation should have a multiple $r$ higher than 0.70 to be acceptable for prediction of $\dot{\mathrm{V}} \mathrm{O}_{2}$ max. In cycling exercise, many factors were used to correct the equations predicting $\dot{\mathrm{VO}}_{2}$ max such as age, ventilation, body mass, lean body mass, power output, blood pressure, ${ }^{1,40-42}$ with a certain level of success. In a study with an arm cranking device in 52 subjects (including 4 paraplegic persons), Chambers et $a l^{43}$ introduced five correction factors in an equation predicting $\dot{\mathrm{V}} \mathrm{O}_{2}$ peak, leading to a coefficient of 0.75 between predicted and measured $\dot{\mathrm{VO}}_{2}$ peak. Furthermore, Rhodes et $a l^{16}$ used blood pressure, age and height to improve the prediction of $\mathrm{VO}_{2}$ peak from the distance covered during a 12-minute field test in a group of persons with SCI $(r=0.69)$.

In our study, three correction factors significantly influenced the accuracy of prediction of $\mathrm{VO}_{2}$ peak: body mass, lean body mass and participation in aerobic exercise. Conversely, the level of injury did not seem to be a valid predictor of $\dot{\mathrm{VO}}_{2}$ peak. Depending on the factors used, the regression equation of prediction showed a multiple $r$ of 0.83 and 0.85 . These correlations are somewhat lower than those presented by other studies ${ }^{10.11 .33}$ which reach values in between 0.88 and 0.97 during arm cranking exercise. Nevertheless, in a review of 13 studies on prediction of $\dot{\mathrm{VO}}_{2}$ max from lower body exercise, $\mathrm{Kasch}^{3}$ found a mean correlation of 0.62 between the predicted and measured values (0.34 to 0.92$)$. The mean percentage of error in the prediction was similar to that presented in studies on lower body exercise. 44,45

It is interesting to observe that lean body mass contributes to increase the accuracy of prediction of $\dot{\mathrm{V}} \mathrm{O}_{2}$ peak. It suggests that a larger muscle mass of upper body may allow a higher efficiency of physiological adapt- 
ation to wheelchair exercise. Conversely, a smaller muscle mass may induce inappropriate adaptations to exercise such as a poor muscle blood flow, a higher muscle tension and a rapid contribution of anaerobic metabolism. The most likely phenomenon that could occur during exercise testing may be an exaggerated response of heart rate at any given submaximal workload, leading to a discrepancy between measured and predicted $\dot{\mathrm{V}} \mathrm{O}_{2}$ peak.

Certain limitations of the present study should be stressed. First, the reality of the research context did not allow us to use a rigorous random sampling procedure; we were only able to recruit a sample of volunteers. So, it could be hypothesized that our subjects had a predetermined positive attitude toward both our study and physical activity. Second, it has been suggested that a multiple regression analysis such as that used to compute the corrected $\dot{\mathrm{VO}}_{2}$ peak requires a large sample. The sample size is relatively small to answer many important questions raised in the study. Third, we were unable to record the preinjury physical activity habits since many subjects could not recall their level of physical activity at the time of injury. However, this variable probably influenced the extent of their participation in physical activity after injury.

Despite the above limitations, our findings suggest that: (1) maximal heart rate in paraplegics during wheelchair exercise is similar to the predicted value $(220-$ age $)$; (2) the relationship between oxygen consumption and power output is linear as well as the relationship between $\% \dot{\mathrm{VO}}_{2}$ peak and heart rate during submaximal wheelchair exercise; and (3) some correction factors (body mass, lean body mass and participation in aerobic exercise) improve the accuracy of prediction of $\mathrm{VO}_{2}$ peak from a submaximal power output and the corresponding heart rate.

There is a need for further research in order to improve the accuracy in the prediction of $\mathrm{VO}_{2}$ peak from a submaximal wheelchair exercise and to determine the relative contribution of correction factors in the explained variance in $\dot{\mathrm{VO}}_{2}$ peak. Moreover, a study with a larger sample could determine whether or not the level and extent of injury as well as the propelling technique influence the prediction of $\dot{\mathrm{VO}} 2$ peak in paraplegic persons.

\section{Acknowledgements}

We are pleased to acknowledge the technical support of Claire Forest, Edgar Tobon, Alex Dumas. The research was supported in part by grants from the Quebec Automobile Insurance Plan, the Quebec March of Dimes and the Centre François-Charon.

\section{References}

1 Astrand PO, Ryhming I (1954) A nomogram for calculation of aerobic capacity (physical fitness) from pulse rate during submaximal work. J Appl Physiol 7: 218-221.

2 Jessup GT, Riggs CE, Beutel-Horvat T, McConnell TJ (1977) The effect of pedalling speed on the validity of the Astrand-Ryhming aerobic work capacity test. J Sports Med 17: 367-371.

3 Kasch FW (1984) The validity of the Astrand and Sjostrand submaximal test. Physician Sportsmed 12(8): 47-54.

4 Bruce RA (1971) Exercise testing of patients with coronary heart disease. Ann Clin Res 3: 323-32.

5 Harrison MH, Bruce DL, Brown GA, Cochrane LA (1980) A comparison of some indirect methods for predicting maximal oxygen uptake. Aviat Space Environ Med 51(10): 1128-33.

6 Kavanagh T, Shephard RJ (1973) The application of exercise testing to the elderly amputees. Can Med Assoc J 108: 314-17.

7 Franklin BA (1985) Exercise testing, training and arm ergometry. Sports Med 2: 100-119.

8 Collett ME, Liljestrand G (1924) The minute volume of the heart in man during some different types of exercise. Scand Arch Physiol 45: 29-42.

9 Glaser RM, Foley DM, Laubach LL, Sawka MN, Suryaprasad AG (1979) An exercise test to evaluate fitness for wheelchair activity. Paraplegia 16: 341-349.

10 Hjeltnes $\mathbf{N}$ (1977) Oxygen uptake and cardiac output in graded arm exercise in paraplegics with low level spinal lesions. Scand J Rehabil Med 9: 107-113. 
11 Kofsky PR, Davis GM, Shephard RJ, Jackson RW, Keene GC (1983) Field testing: Assessment of physical fitness of disabled adults. Eur J Appl Physiol 51: 109-120.

12 Sawka MN (1986) Physiology of upper body exercise. Exerc Sport Sci Rev 14: 175-211.

13 McCafferty Wr, Horvath SM (1977) Specificity of exercise and specificity of training: a subcellular response. Res $Q$ 48: $358-371$.

14 Glaser RM, Sawka MN, Brune MF, Wilde SW (1980) Physiological responses to maximal effort wheelchair and arm crank ergometry. J Appl Physiol 48(6): 1060-64.

15 Gordon EE (1952) Energy cost of various physical activities in relation to pulmonary tuberculosis. Arch Phys Med 33: 201-209.

16 Rhodes EC, McKenzie DC, Coutts KD, Rogers AR (1981) A field test for the prediction of aerobic capacity in male paraplegics and quadriplegics. Can J Appl Sport Sci 6(4): 182-86.

17 Voigt ED, Bahn D (1969) Metabolism and pulse rate in physically handicapped when propelling a wheelchair up an incline. Scand J Rehabil Med 1: 101-106.

18 Gass GC, Camp EM (1979) Physiological characteristics of trained Australian paraplegic and tetraplegic subjects. Med Sci Sports Exerc 11(3): 256-9.

19 Brouha L, Krobath $\mathrm{H}$ (1967) Continuous recording of cardiac and respiratory functions in normal and handicapped persons. Human factors 67: 567-572.

20 Coutts KD, Rhodes EC, McKenzie DC (1983) Maximal exercise responses of tetraplegics and paraplegics. $J$ Appl Physiol 55(2): 479-82.

21 Brattgard SO, Grimby G, Höök O (1970) Energy-expenditure and heart rate in driving a wheelchair ergometer. Scand J Rehabil Med 2: 143-48.

22 Burkett LN, Chisum J, Cook R, Norton B, Taylor B, Ruppert K et al (1987) Construction and validation of a hysteresis brake wheelchair ergometer. Adaptive Phys Activity $Q$ 4: 60-71.

23 McCann BC (1984) Classification of the locomotor disabled for competitive sports: theory and practice. Int J Sports Med 5: 167-70.

24 Fitness Canada (1986) Canadian Standardized Test of Fitness (CSFT). Operations Manual. 3rd ed. Fitness Canada, Ottawa.

25 Womersley J, Durnin JV (1977) A comparison of skinfold method with extend of overweight and various weight-height relationships. Brit J Nutr 38: 271-84.

26 American College of Sports Medicine (1986) Guidelines for Exercise Testing and Prescription. 3rd ed. Lea \& Feberger, Philadelphia.

27 Godin G, Shephard RJ (1985) A simple method to assess exercise behaviour in the community. Can J Appl Sport Sci 10(3): 141-146.

28 Health and Welfare Canada (1988) Canadian Guidelines for Healthy Weights. Ottawa.

29 Franklin BA (1989) Aerobic exercise training programs for the upper body. Med Sci Sports Exerc 21(5): S141-S148.

30 Martel G, Noreau L, Jobin J (1991) Physiological responses to maximal exercise on arm cranking and wheelchair ergometer with paraplegics. Paraplegia 29: 447-56.

31 Whiting RB, Dreisinger TE, Hayden CR (1984) Wheelchair exercise testing: comparison of continuous and discontinuous exercise. Paraplegia 22(2): 92-98.

32 Sedlock DA, Knowlton RG, Fitzgerald PI (1990) Circulatory and metabolic responses of women to arm crank and wheelchair ergometry. Arch Phys Med Rehabil 71(2): 97-100.

33 Hjeltnes N (1986) Cardiorespiratory capacity in tetra and paraplegia shortly after injury. Scand J Rehabil Med 18(2): 65-70.

34 Franklin BA, Vander L, Wrisley D, Rubenfire M (1983) Aerobic requirements of arm ergometry: implications for exercise testing and training. Physician Sportsmed 11: 81-90.

35 De Bruin MI, Binkhorst RA (1984) Cardiac output of paraplegics during exercise. Int J Sports Med 5: 175-176.

36 Davis GM, Shepard RJ (1988) Cardiorespiratory fitness in highly active versus inactive paraplegics. Med Sci Sports Exerc 20(5): 463-468.

37 Davies CTM (1968) Limitations to the prediction of maximal oxygen intake from cardiac frequency measurements. J Appl Physiol 24: 700-706.

38 Legge BJ, Banister EW (1986) The Astrand-Ryhming nomogram revisited. J Appl Physiol 61(3): 1203-1209.

39 Metz KF, Alexander JF (1971) Estimation of maximal oxygen intake from submaximal work parameters. Res $Q$ 42(2): 187-191.

40 Mastropaolo JA (1970) Prediction of maximal $\mathrm{O}_{2}$ consumption in middle-aged men by multiple regression. Med Sci Sports Exerc 2(3): 124-127.

41 Hermiston RT, Faulkner JA (1971) Prediction of maximal oxygen uptake by a stepwise regression technique. J Appl Physiol 30(6): 833-837.

42 Eston RG, Brodie DA (1986) Responses to arm and leg ergometry. Brit J Sports Med 20(1): 4-6.

43 Chambers RS, Nelson AG, Fisher AG (1985) Prediction of upper extremity $\mathrm{VO}_{2}$ max through submaximal arm cranking tests. Med Sci Sports Exerc 17: 230 (abstract).

44 Astrand PO, Rodahl K (1977) Textbook of Work Physiology. 2nd ed. McGraw-Hill Book Co, New York.

45 Shephard RJ (1984) Test of maximum oxygen intake: A critical review. Sports Med 1: 99-124. 